\title{
Article
}

\section{Convergence: A Story of Quantiles and Spillovers}

Kostov, Philip and Le Gallo, Julie

Available at http://clok.uclan.ac.uk/12451/

Kostov, Philip ORCID: 0000-0002-4899-3908 and Le Gallo, Julie (2015)

Convergence: A Story of Quantiles and Spillovers. Kyklos: International Review Of Social Sciences, 68 (4). pp. 552-576. ISSN $0023-5962$

It is advisable to refer to the publisher's version if you intend to cite from the work. http://dx.doi.org/10.1111/kykl.12093

For more information about UCLan's research in this area go to http://www.uclan.ac.uk/researchgroups/ and search for < name of research Group>.

For information about Research generally at UCLan please go to http://www.uclan.ac.uk/research/

All outputs in CLoK are protected by Intellectual Property Rights law, including Copyright law. Copyright, IPR and Moral Rights for the works on this site are retained by the individual authors and/or other copyright owners. Terms and conditions for use of this material are defined in the policies page.

\section{CLoK}

Central Lancashire online Knowledge www.clok.uclan.ac.uk

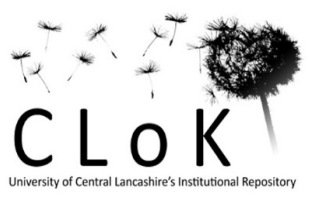


This is a post-print of Kostov, P. and J. Le Gallo (2015) Convergence: a story of quantiles and spillovers, Kyklos, 68(4), 552-576. The definitive version is available at http://doi.org/10.1111/kykl.12093

\title{
Convergence: a story of quantiles and spillovers
}

Philip Kostova and Julie Le Gallo ${ }^{b}$

a Lancashire Business School, Greenbank Building, GR032, Preston, PR1 2HE, UK.

b CRESE, Université de Franche-Comté, 45D, Avenue de l’Observatoire, 25030 Besançon Cedex, France

\begin{abstract}
:
In this paper, we revisit the analysis of cross-country convergence by combining spatial econometrics and panel quantile regressions to estimate conditional $\beta$-convergence models. Moreover, we use both exogenous and endogenous weight matrices. Our results show that indeed the effects of initial per capita income, investment rate, population growth and human capital on growth rates vary considerably across the estimated quantiles. Convergence is not a generalized phenomenon across the conditional growth distribution. Moreover, while using exogenous spatial weight matrices does not substantially alter the findings found in a-spatial models, it appears that endogenous weights dramatically affect the estimates of the convergence process.
\end{abstract}

Key words: Cross-country convergence, quantile regressions, panel data, spatial autocorrelation

JEL codes: $C 21, C 23,047$ 
This is a post-print of Kostov, P. and J. Le Gallo (2015) Convergence: a story of quantiles and spillovers, Kyklos, 68(4), 552-576. The definitive version is available at http://doi.org/10.1111/kykl.12093

\section{Introduction}

Given the persistent disparities in aggregate growth rates between countries, it should come as no surprise that the question of income convergence has received a lot of attention in the last three decades. Following the seminal contributions of Barro (1991) and Mankiw et al. (1992), the empirical literature on the subject tends to adopt a common approach that consists in regressing output growth rates on a number of variables using a cross-section or a panel of countries. These variables typically include initial per capita income, investment share, population growth and schooling as a measure of human capital accumulation. Then, the finding that the coefficient on initial level of per capita income is negative is generally interpreted as evidence of crosscountry conditional convergence. This is known as the $\beta$-convergence concept.

However, a number of contributions have pointed out that there are substantial problems and pitfalls in estimating and interpreting growth regressions, such as, for instance, the lack of robustness of the explanatory variables (Levine and Renelt, 1992) or their endogeneity because of omitted variables or measurement errors (Temple, 1998). We focus here on two other important criticisms.

The first concerns the assumption of parameter homogeneity in the convergence equations, meaning that the parameters of the models are assumed to be countryinvariant. However, wide evidence for convergence clubs between countries has been found (Durlauf and Johnson, 1995; Durlauf, 2000). Several methods have been suggested to characterize parameter heterogeneity, such as regression trees (Durlauf and Johnson, 1995) or other forms of semi-parametric varying coefficient models (Desdoigts, 1999). One particular appealing method to deal with parameter heterogeneity is the use of quantile regression models. Indeed, when applying a quantile approach to convergence analysis, it is possible to use each estimated quantile to describe a particular segment of the conditional distribution of income growth. Hence, this analysis provides a more complete description of the relationship between income growth rate and initial level of per capita income and other variables and has potentially important policy implications in terms of the best ways to foster growth depending on the position of the country in the conditional distribution of income growth rate. Such an 
This is a post-print of Kostov, P. and J. Le Gallo (2015) Convergence: a story of quantiles and spillovers, Kyklos, 68(4), 552-576. The definitive version is available at http://doi.org/10.1111/kykl.12093

approach to convergence has been used, among others, by Cunningham (2003), Barreto and Hughes (2004), Canarella and Pollard (2004), Foster (2008), Ram (2008) and Dufrenot et al. (2010). Note however that all these papers only apply cross-sectional versions of quantile regressions methods. This is unfortunate as it has been argued that the cross-sectional versions of the $\beta$-convergence model are affected by unmodelled country-specific unobserved effects on output levels so that panel versions of the model are preferable (Islam, 1995). By extension, panel versions of quantile regressions should be used in convergence models to control both for parameter heterogeneity and unobserved country effects.

The second concern deals with the assumption of independence between countries. However, there is now wide recognition that countries are not exchangeable. Hence, specific econometric techniques should be adopted to account for this cross-sectional interdependence. In the regional science literature, a large number of papers have applied spatial econometrics to explicitly include spatial autocorrelation in convergence regressions on regional data (see Abreu et al., 2005; Ertur and Le Gallo, 2009 or Rey and Le Gallo, 2009 for literature reviews). The recognition that space matters and that spillovers are an important part of the growth process is also apparent in cross-country analyses. In particular, sound theoretical foundations for the inclusion of spatial dependence in $\beta$-convergence models is provided by Ertur and Koch (2007) who show how a spatial econometric specification of the $\beta$-convergence model can be obtained from a theoretical growth model with Arrow-Romer externalities and spatial externalities implying inter-country technology interdependence. They then apply their model to cross-country data and indeed find wide evidence for spatial autocorrelation. In this context, our paper contributes to the literature in two ways. On the one hand, to the best of our knowledge, this is the first paper that applies panel quantile regressions to analyse cross-country $\beta$-convergence. On the other hand, we explicitly take into account spatial spillovers by including a spatial lag term in our specification. While spatial versions of quantile regressions exist (Kostov, 2009, 2013; Su and Yang, 2011), they still remain scarce and none concern the issue of convergence. Moreover, not only do we consider exogenous weights matrices based on geographical distance, as is usual in the spatial econometric literature, but we also draw on recent papers that consider endogenous weight matrices in spatial econometric models (Kelejian and Piras, 2014). 
This is a post-print of Kostov, P. and J. Le Gallo (2015) Convergence: a story of quantiles and spillovers, Kyklos, 68(4), 552-576. The definitive version is available at http://doi.org/10.1111/kykl.12093

In all, we intend to provide a broader and complete view of cross-country convergence by combining panel quantile regressions with spatial econometric considerations. Our approach has several advantages. First, we are able to detect the countries which, given their endowments, grow faster (resp. slower) than the other comparable countries: these countries are over-achievers (resp. under-performers). Second and as a consequence, our framework allows uncovering complex patterns of conditional convergence across the conditional distribution and the way the speed of convergence varies across quantiles. As we detail below, our expectation is that the speed of conditional convergence is significant and increases with quantiles as higher quantiles group the over-achievers. Third, we can provide a detailed account of the way the effects of the control variables (average savings, population growth and human capital) on income growth rate vary across quantiles. These effects may indeed be heterogeneous depending on the position of the countries in the conditional distribution. Hence, detecting precisely how they impact growth is important from a policy point of view to specify the relevant leverages to enhance growth.

Our results show that indeed the effects of initial per capita income, investment rate, population growth and human capital on growth rates vary considerably across the estimated quantiles. Convergence is not a generalized phenomenon across the conditional growth distribution. In particular, while a mean regression implies a coefficient for the lagged income significant and negative equal to -0.005 , we only find conditional convergence in the upper part of the distribution, with coefficients up to -0.015 for exogenous weights matrices. Moreover, while using exogenous spatial weight matrices does not substantially alter the findings found in a-spatial models, it appears that endogenous weights dramatically affects the estimates of the convergence process: the convergence effect appears for larger part of the distribution and is generally stronger. Moreover, while for the exogenous specifications, the impact of human capital is only significant for the upper part of the distribution; it is significant and positive for the whole distribution in the endogenous case.

This paper proceeds as follows. In the next section we briefly review the quantile approach in econometrics and show how it can be extended to panel data and/or spatial 
This is a post-print of Kostov, P. and J. Le Gallo (2015) Convergence: a story of quantiles and spillovers, Kyklos, 68(4), 552-576. The definitive version is available at http://doi.org/10.1111/kykl.12093

data. We then present (Section 3) the data and weight matrices used in the empirical analysis. Section 4 outlines our estimation results. Finally Section 5 concludes.

\section{Methodology}

\section{$2.1 \quad$ Formulation of the general model}

The general econometric model employed in the present paper can be expressed as follows:

$$
y_{t}=\lambda_{\tau} W_{t} y_{t}+X_{t} \beta_{\tau}+\alpha_{\tau}+u_{\tau f} \quad t=1 \ldots T
$$

In (1) above $y_{t}$ is a $(N, 1)$ vector of the dependent variable for all cross-sectional observations in time $t, t=1 \ldots T$. The $(N, K)$ matrix $X_{t}$ similarly contains the covariates for time $t$ and $W_{t}$ is a $(N, N)$ cross-sectional spatial weighting matrix for time $t$. We also include a vector of individual 'fixed effects' ( $\alpha_{\tau}$ below) for each individual $i$. All coefficients are dependent on a given quantile $0<\tau<1$. Ignoring the individual effects $\alpha_{\tau}$, which make the model in equation (1) infeasible, is equivalent to a cross sectional quantile spatial autoregression (see Su and Yang, 2011 and Kostov, 2009, 2013) for a period $t$. However if the above formulation holds for each period $t(1 \leq t \leq T)$, then we can combine all these equations implied by (1) for $\forall t(1 \leq t \leq T)$ to obtain the following panel quantile spatial autoregressive formulation we employ in this paper:

$y=\lambda_{\tau} W_{s} y+X \beta_{\tau}+\psi_{\tau}+u_{\tau}$

st $q_{z}\left(u_{\tau} \mid W_{s} y, X\right)=0$

In equation (2), $\boldsymbol{u}_{\tau}, \boldsymbol{y}$ and $X$ are the stacked versions of $\boldsymbol{u}_{\tau, t}, y_{t}$ and $X_{t}$ over time and $W_{s}$ is a $(N T, N T)$ block diagonal matrix formed by the cross-sectional spatial weighting matrices $W_{t}$. The block-diagonal structure excludes time-dependence. Moreover, in the case of a balanced panel and time-invariant spatial weighting matrices, these will be identical: $W_{t}=W, \forall t$ and $W_{s}=I_{T} \otimes W$. We also include a similarly stacked vector of individual 'fixed effects' ( $\psi_{\tau}=e_{T} \otimes \alpha_{\tau}$ ) yielding the panel quantile spatial autoregressive 
This is a post-print of Kostov, P. and J. Le Gallo (2015) Convergence: a story of quantiles and spillovers, Kyklos, 68(4), 552-576. The definitive version is available at http://doi.org/10.1111/kykl.12093

formulation we employ in this paper. Equation (3) represents the linear quantile restriction that states that the $\tau$ th conditional quantile is zero. It is the equivalent to the zero-mean restriction on the residuals in a mean regression model.

While the conventional mean regression models the mean of a dependent variable and basically assumes that the same relationship is applicable over the whole distribution of the response, the quantile regression models the conditional quantile(s) and hence allows different effects of the covariates over the conditional distribution. Consequently, estimating quantile regression over a range of quantiles allows one to model the whole conditional distribution.

Consequently, with this specification, we can account for both a 'spatial' spillover process (via the spatial lag $\lambda_{\tau}$ ) and individual heterogeneity (via the individual effects in $\left.\psi_{\tau}\right)$

\subsection{Interpretation of coefficients in spatial panel quantile models}

Excluding the individual effects stacked in $\boldsymbol{\psi}_{\tau}$ would reduce our model to the 'spatially autoregressive quantile regression model' of Su and Yang (2011). Kostov $(2009,2013)$ refers to this cross sectional version as simply "spatial quantile regression", but such a term could be easily confused with other quantile regression formulations in the context of spatially dependent data that do not involve endogeneity, but use spatially varying coefficients (e.g. Hallin et al., 2009; Reich et al., 2011; Lum and Gelfand, 2012; Chen et al., 2012).

One should nevertheless have to be careful in drawing analogies between spatial quantile autoregressions and mean models, since quantile models are intrinsically nonlinear. In particular, inference in the mean spatial autoregression relies on the computation of the partial derivatives, following LeSage and Fischer (2008). As Kostov (2013) noted for the spatial quantile autoregression, such a computation can be done similarly to the linear spatial lag model. However, the interpretation of these would be quite different due to the nonlinearity of the quantile regression. To clarify this, let us rewrite the non-panel version of (2) in the following reduced equivalent form, as in the mean spatial autoregression literature:

$$
y=\left(I-\lambda_{\tau} W_{s}\right)^{-1} X \beta_{\tau}+\left(I-\lambda_{\tau} W_{s}\right)^{-1} \psi_{\tau i}+\left(I-\lambda_{\tau} W_{s}\right)^{-1} u_{\tau}
$$


This is a post-print of Kostov, P. and J. Le Gallo (2015) Convergence: a story of quantiles and spillovers, Kyklos, 68(4), 552-576. The definitive version is available at http://doi.org/10.1111/kykl.12093

Equation (4) above is the basis for formulating the average direct and indirect effects and it can be used to derive these in exactly the same way as this is done in the mean spatial literature. However, there is one important difference. The mean models are identified by the corresponding conditional mean restriction (as opposed to the conditional quantile restriction in (3) above). Viewing (4) as a linear quantile regression model means to associate it with a linear quantile restriction, similar to (3). However, in general the quantile restriction implied in this would be a different one (to the one given in (3)). Hence viewing (4) as a model representation produces a very different model from the one specified in (2). Whether one wants to do this is another story since the actual interpretation for these two alternative models would be quite different.

The model in (2) above can be considered as both a spatially autoregressive model with added individual effects, or alternatively as a 'fixed effects' panel quantile model with an endogenous spatial lag. The latter is more convenient from an estimation point of view. Therefore our estimation strategy follows this logic: we account for the spatial lag endogeneity in a panel quantile regression framework. This allows us a gradual transition from the simpler panel quantile regression to our model. Below we briefly review the issues and estimators for panel quantile regression models.

\subsection{Estimation issues for panel quantile models}

Introducing individual effects to account for possible unobserved individual heterogeneity in quantile models leads to complications. Indeed, since the quantile regression is essentially a non-linear model, there is no transformation (such as the within transformation, time differencing, orthogonal deviations used to cancel the individual effects in linear models) that can eliminate the individual effects. Hence, these will have to be estimated directly by including individual dummies. Such a strategy can however lead to a version of the incidental parameter problem (when the crosssectional dimension increases with the sample size, i.e. $N$ going to infinity with fixed $T$ in a more usual terminology) resulting in inconsistent estimates. Rosen (2009) and Chernozhukov et al. (2009) study these identification issues in more detail.

Probably the first and best-known approach is the proposal of Koenker (2004) who suggested shrinking the 'fixed effects' (via $L 1$ penalty) to overcome the bias. The idea is very simple. While the introduction of individual effects increases the variability of their 
This is a post-print of Kostov, P. and J. Le Gallo (2015) Convergence: a story of quantiles and spillovers, Kyklos, 68(4), 552-576. The definitive version is available at http://doi.org/10.1111/kykl.12093

estimates, shrinking them towards a common value (via the $L 1$ penalty) helps reducing this variability. The asymptotics in this case relies on both $T$ and $N$ growing to infinity (at the same rate, so it is not applicable to short-time panels). In practice, implementing the 'fixed effect' quantile regression is relatively straightforward. The main stumbling block is the choice of optimal amount of shrinkage. Lamarche (2010) showed that under some regularity conditions, the regularised quantile estimator of Koenker (2004) is asymptotically unbiased. Then, choosing the amount of shrinkage that minimises the asymptotic variance is equivalent to minimising the average mean square error (AMSE) of the estimator.

The proposal of Koenker (2004) is known as the 'fixed effects' (FE) approach to panel quantile regression and has been much more extensively studied and developed than any of the other alternatives. Consequently, fixed effects models have been dominating the quantile panel modelling literature. One should however be very careful when directly comparing quantile models with their linear counterparts, since direct generalisations are not always possible.

We now briefly review some alternatives to the 'fixed effects' approach.

The second most well-known estimator is probably that of Abrevaya and Dahl (2008). They impose a particular structure on the relationship between individual effects and regressors resulting in a correlated-random-effects (CRE) quantile regression model. As a result, they obtain a correlated random coefficients model that can be estimated consistently using standard quantile regression techniques. The main problem here from practical point of view is the need to specify the correlation structure (which may be far from obvious). The other issue with the Abrevaya and Dahl (2008) estimator is that since it uses the Chamberlain (1982) projection approach, it is only applicable to balanced panels. Bache et al. (2013) propose a restricted version in which, when specifying the correlation structure, they replace the regressors correlated with the individual effects by a weighted average of their time realisations, which, in the simplest case of unweighted averages, yields their time means and hence can be applied to unbalanced panels.

It is worth noting at this point that the terminology used in the panel quantiles literature mimicking the linear panel modelling tradition is slightly misleading. Indeed, since all 
This is a post-print of Kostov, P. and J. Le Gallo (2015) Convergence: a story of quantiles and spillovers, Kyklos, 68(4), 552-576. The definitive version is available at http://doi.org/10.1111/kykl.12093

quantile coefficients are in principle variable (by definition) they resemble the random effects in the linear model case. Therefore, technically speaking, the quantile 'fixed effects' are essentially shrunken random effects. Given this distinction, it would have been much more natural to use 'random effects' specification. In particular, such random effects formulation would arise naturally if a Bayesian modelling framework is adopted. As shown e.g. in Yuan and Yin (2010) if one penalises the subjects specific effects by an $L 2$ (instead of $L 1$ as in Koenker, 2004) penalty, since the $L 2$ penalty can be expressed as the logdensity of a Gaussian random effects prior, this naturally leads to a Bayesian random effects approach. Following Yu and Moyeed (2001) the Bayesian approach to quantile regression uses the asymmetric Laplace (ASL) density for the error terms to formulate Bayesian quantile regression models. The location-scale mixture representation of the ASL distribution, proposed by Kotsumi and Kobayashi (2009) allows one to reformulate this Bayesian quantile model as an alternative conditionally Gaussian representation and hence apply existing sampling techniques available for Gaussian models (see e.g Reed and Yu, 2009). Kostov and Davidova (2013) use the equivalence between Laplace prior and $L 1$ penalty (aka Bayesian lasso) to construct a Bayesian equivalent to the Koenker (2004) estimator, but their approach is computationally more demanding than that of Yuan and Yin (2010). Canay (2011) proposes a two-step estimator that is particularly easy to implement. However, he imposes the restriction that the individual effects do not change across quantiles. Moreover, in addition to being much more restrictive, Canay's (2011) estimator requires a balanced panel dataset.

In considering alternative panel quantile models, one needs to take into account the theoretical properties of the alternative estimators and their computational requirements. Here we will not discuss the former and will briefly consider the practical implementation issues.

Although by far the most popular, the Koenker (2004) estimator is the most demanding computationally in that the search for optimal amount of shrinkage carries considerable computational costs. Bayesian estimation via Markov Chain Monte Carlo (MCMC) simulation is always computationally demanding, but workable approximations, such as variational inference (Waldmann and Kneib, 2014), or (integrated nested) Laplace 
This is a post-print of Kostov, P. and J. Le Gallo (2015) Convergence: a story of quantiles and spillovers, Kyklos, 68(4), 552-576. The definitive version is available at http://doi.org/10.1111/kykl.12093

approximation (Yue and Rue, 2011) are available to reduce the computational costs. Finally, the CRE approach is computationally the most appealing, although it requires practical examination and justification of the identification assumptions and hence may not always be applicable to the specific estimation problem.

In the first part of our empirical analysis, where we don't allow for spatial effects, the FE and CRE models are estimated jointly at all considered quantiles by weighting the individual quantile objective functions. Equal weighting for all quantiles is used. The optimal amount of shrinkage for the FE model is calculated following Lamarche (2010). The individual effects in the CRE models are allowed to be correlated with the lagged income. With regard to the random effect formulation, we have implemented Bayesian MCMC inference using the sampling scheme suggested in Waldman et al. (2013) which avoids the mixing and convergence issues found by Yue and Rue (2011). We have implemented the variational approximation as detailed in Waldmann and Kneib (2014). Taking into account the endogenous spatial lag can generalise the above estimators to the model we consider in this paper. For simplicity we will only focus on the nonBayesian approaches. Harding and Lamarche (2009) plugged-in the instrumental variables quantile regression estimator of Chernozhukov and Hansen $(2005,2006)$ to obtain a panel quantile regression under endogeneity. Since the estimator of Chernozhukov and Hansen $(2005,2006)$ is numerically convenient (i.e. it involves search over one dimensional grid in the case of a single endogenous variable), is the basis of the implementation of Kostov (2009) and its properties for spatial quantile autoregressive models have been studied in Su and Yang (2011), such implementation is in the spirit of previous research in this area. In principle, there is nothing preventing one combining in the same way alternative endogeneity and panel estimators, although the theoretical properties of such alternative combined estimators remain to be established. We applied the Chernozhukov and Hansen $(2005,2006)$ estimator to the panel 'fixed effects' and 'quantile' formulation of Koenker (2004) by instrumenting the endogenous spatial lag by spatial lags of the exogenous variables as in Kostov (2009, 2013) and Su and Yang (2011). However, the optimal shrinkage determination in the 'fixed effects' model is computationally demanding. For this reason, we have also applied the control function approach (see Lee, 2007) to control for the endogeneity of the 
This is a post-print of Kostov, P. and J. Le Gallo (2015) Convergence: a story of quantiles and spillovers, Kyklos, 68(4), 552-576. The definitive version is available at http://doi.org/10.1111/kykl.12093

spatial lags, since it avoids two sets optimisation (over the shrinkage parameter and the spatial lag coefficients). The results from the two alternative approaches were not significantly different. We only report the control function approach estimates for the CRE estimators.

\section{Data and weight matrices}

\subsection{Data}

We base our analysis on the well-known Mankiw et al. (1992) specification to evaluate the impact of saving, population growth, human capital and location on the growth rate of per capita income. Our dependent variable ( $y_{t}$ in (2)) is a 5-year average of growth rate of per capita GDP. Following Mankiw et al. (1992), the explanatory variables ( $X_{t}$ in (2)) should be initial per capita GDP and proxies of average saving rate, population growth and average human capital.

Specifically, the data for per-capita GDP, saving, population growth are extracted from the Heston et al. (2012) Penn World Table (PWT version 7.1), which contain information on real income, investment and population for a large number of countries. With respect to the control variables, we proxy population growth as the average growth of the working age population (15 to 64) on a basis of 5-year interval. The number of workers needed for the computation of this variable has been obtained as: RGDPCH *POP/RGDPW, where RGDPCH is real GDP per capita computed by the chain method, RGDPW is real-chain GDP per worker and POP is the total population. The savings rate is measured as the average share of gross investment in GDP for each fiveyear interval. Finally, the data on human capital is extracted from the Barro and Lee (2011) dataset. We use the educational attainment in secondary school for total population over age 15. Again, these data are available for five-year intervals. Hence the data used in this study consists of 5-year averages for the per-capita GDP, saving, population growth and human capital measures. In the empirical specification, we use the lagged value for the GDP per capita as initial income measure, which in this case is the value for the previous 5 years. Such aggregation is a standard practice in panel data growth studies and have been shown to improve significance of the result in accordance with theoretical predictions (Krueger and Lindahl, 2001). 
This is a post-print of Kostov, P. and J. Le Gallo (2015) Convergence: a story of quantiles and spillovers, Kyklos, 68(4), 552-576. The definitive version is available at http://doi.org/10.1111/kykl.12093

These variables are constructed for an unbalanced sample of 120 countries over the period 1955-2010. Hence we have $t=1 \ldots 11$ and $N=120$. The same dataset is used in the spatial models. The availability of distance metrics to construct the spatial weighting matrices imposes further exclusions. With regard to the exogenous case, since we use readily available geographical information, this results in an identical sample. For the endogenous spatial weighting matrix however the availability of data to construct the spatial weighting matrices excludes 20 countries. Moreover, since the market potential data varies from year to year, its availability further restricts the years for which the exogenous models can be implemented. The countries in the dataset and the years of availability in both cases are displayed in Table S.1 in a supplementary appendix.

\subsection{Spatial weight matrices}

To avoid confusion below, when we mention a spatial weighting matrix, we mean the cross-sectional ones. Conversely, we refer to $W_{s}$ in equation (2) above which is constructed from these cross-sectional matrices, as the 'global' spatial weighting matrix. In the empirical application, we compare two categories of weight matrices: exogenous matrices purely based on the spatial configuration of the countries on the one hand and endogenous matrices based on economic characteristics on the other hand.

With respect to exogenous weight matrices, we use three different specifications: (i) A binary $W$ with $100 \mathrm{~km}$ definition of neighbourhood (i.e. countries within $100 \mathrm{~km}$ of each other being defined as neighbours); (ii) A binary $W$ with the neighbourhood defined as the 10 nearest (geographically) neighbours (iii) Finally a $W$ with inverse squared (geographical) distances as weights and cut-off definition of the neighbourhood, as explained below. One can view the above as illustrations for three different types of spatial weighting matrices. We have tried several alternative representations for each of these three types (i.e. different definitions of neighbourhood as distance in (i) or number of neighbours in (ii) as well as inverse distances and alternative cut-off definitions in (iii)) and the estimation results are insensitive to such alternative parameterisations. All the presented specifications (and the omitted ones) share the common property that each country has at least one neighbour for each year.

For all the cases above, we create separate $W$ for each year in the dataset and combine these into a 'global' $W_{S}$. Moreover, for the last case we apply the following cut-off rule. 
This is a post-print of Kostov, P. and J. Le Gallo (2015) Convergence: a story of quantiles and spillovers, Kyklos, 68(4), 552-576. The definitive version is available at http://doi.org/10.1111/kykl.12093

We calculate the number of neighbours for each country and each year. For each annual $W$ we then calculate an annual 'threshold' as the minimum weight (equivalently the maximum distance) for which every country has at least one neighbour for that particular year. This allows us to take the maximum over all annual thresholds and use this as cut-off, by setting all weights below this threshold to zero. The above procedure ensures that locally (i.e. for every separate year) each country has at least one neighbour). Since all exogenous weights above are calculated from geographical measures of proximity, the underlying 'local' spatial weighting matrices are timeinvariant. However due to the unbalanced nature of our panel data combining the 'local' (i.e. annual) $W$ into a global one results in a global spatial weighting matrix replicating the structure of the panel data.

With respect to endogenous weight matrices, we use data on market potential from Mayer (2009) for the period 1960-2003. The dataset is available at http://www.cepii.fr/anglaisgraph/bdd/marketpotentials.htm. Since we use 5-year intervals, we have used the 2003 market potential data for 2005. The market potential concept (labelled Market Access (MA) by Redding and Venables (2004) or Real Market Potential (RMP) by Head and Mayer (2004)) relates the level of factors' income of a country to its export capacity. More specifically, the level of factor incomes in each country (since in the case considered here labour is the only factor, it means the wages) can be explained by a weighted sum of expenditures of all countries in the world (the sample). The weights are given by the bilateral trade costs calculated by export destination. It is this weighted sum that is termed market potential. Hence the market potential reflects the structure of international trade and countries with similar market potential face similar terms of trade defined with regard to the factor under consideration (i.e. labour). Increasing wages outside a country relative to its own level of wages would therefore increase its market potential measure. Therefore one can view the market potential as a trade competitiveness measure (with regard to labour in this instance). Using the differences amongst the countries' market potential as distances to construct spatial weighting matrices defines a spillover process representing trade competition reflecting returns for labour, while holding returns to other factors constant. 
This is a post-print of Kostov, P. and J. Le Gallo (2015) Convergence: a story of quantiles and spillovers, Kyklos, 68(4), 552-576. The definitive version is available at http://doi.org/10.1111/kykl.12093

The endogenous $W$ is hence based on the market potential. The latter is available on annual basis so that the resulting spatial weights are time specific. The market potential based $W$ is based on the pairwise differences in the market potentials for different countries and the corresponding 'spatial' weights are calculated as inverse distances. The construction of a global $W$ is implemented using a cut-off rule similarly to the exogenous case, i.e. selecting a global cut-off that ensures each country has at least one neighbour in each separate year.

It is clear from the nature of the differences underlying the construction of this spatial weighting matrix that the exogeneity assumption can no longer hold. Consequently, we used the sum of bilateral distances and the sum of estimated bilateral trade costs for each pair of countries to construct instruments for the endogenous $W$, following the approach proposed by Kelejian and Piras (2014). These instrumental matrices are similarly calculated for each separate year and then combined together. We have also implemented alternative sets of instruments (only sum of bilateral distances or only sum of estimated bilateral trade costs based matrices) as well as inversed squared distances based $\mathrm{W}$. These alternative specifications produce very similar results.

Finally, we standardize all the weight matrices (both exogenous and endogenous) using the procedure described in Kelejian and Prucha (2010) and based on the spectral radius. The reason we prefer the spectral radius based procedure over the more commonly used standardisation using row sums is that the latter converts absolute distance-based interactions into relative distance-based interactions, hence changing the information content of the connection structure.

\section{Results}

Before discussing the results, it is useful to recall the way in which the quantile regression results should be interpreted in our context of conditional $\beta$-convergence models. In particular, note that the word 'conditional' may be used for two different concepts. Indeed, we estimate conditional $\beta$-convergence models: compared to absolute $\beta$-convergence, additional control variables are added, which implies that each country converges to its own steady state. These are estimated in the context of conditional quantile regressions, i.e. conditional to the distribution of income growth rate. Then, the 
This is a post-print of Kostov, P. and J. Le Gallo (2015) Convergence: a story of quantiles and spillovers, Kyklos, 68(4), 552-576. The definitive version is available at http://doi.org/10.1111/kykl.12093

upper conditional quantiles represent the countries which, given their endowments (i.e. savings, population growth, human capital and initial income), grow faster than the other comparable countries (i.e. faster than they should). These countries can be labelled as "over-achievers" (Barreto and Hugues, 2004). Once again, note that these do not need to be the unconditionally faster growing countries. On the contrary, lower conditional quantiles group the "under-performers". Assuming that the process of conditional $\beta$-convergence holds, this has the following implications for our empirical model. In mean models, the negative sign of the lagged income is an indication of conditional convergence. In the quantile regression specification, the same applies, but we can have different patterns of conditional convergence (negative sign), nonconvergence (no effect) or divergence (positive sign) across the conditional distribution. Larger negative coefficient of lagged income implies faster convergence. Looking at the quantile distribution, since upper quantiles signify conditionally faster growing countries, one should expect that the latter should also converge faster. In other words faster growth should be associated with better catching up. Hence one would expect the coefficient of lagged income to be both negative and increasing in magnitude with the quantiles. Deviations from this expectation could be interpreted as violations of the assumed convergence to a single steady state dynamics.

\subsection{Non-spatial panel quantile models}

Before proceeding to the main panel data estimators, it would be useful to put these in comparative perspective. Figure 1 contains a comparison of the fixed effects quantile regression estimates (which is the main panel QR estimator we consider) with simple OLS estimates and standard quantile regression (i.e. respectively pooled versions of mean and quantile regressions).

A range of quantile regression models from the $0.05^{\text {th }}$ to the $0.95^{\text {th }}$ quantile at 0.01 increments are estimated. In this particular case the fixed effects and standard quantile regression results appear similar. This is due to the fact that the optimal shrinkage term applied to the fixed effects is quite large, hence shrinking them more severely towards zero and moving panel quantile estimates closer to the conventional quantile regression ones. This similarity can be attributed to using 5 year averages which reduce the year on year variability in the data (more pronounced differences are observed if non- 
This is a post-print of Kostov, P. and J. Le Gallo (2015) Convergence: a story of quantiles and spillovers, Kyklos, 68(4), 552-576. The definitive version is available at http://doi.org/10.1111/kykl.12093

averaged data is used instead). However ignoring the individual country effects leads to underestimation of the standard errors and the confidence intervals produced by simple quantile regressions are tighter than what they should be, resulting in potentially inefficient inference.

[Figure 1 around here]

We present results from non-spatial panel quantile models on Figure 2. We applied four different specification/estimation methods:

- FE refers to the fixed effects panel quantile regression (Koenker, 2004) with optimal shrinkage estimated following Lamarche (2010);

- CRE is the correlated random effects estimator of Abrevaya and Dahl (2008) amended following Bache et al. (2013) to allow for unbalanced panels;

- MCMC is a Bayesian formulation with country random effects with Dirichlet process priors, estimated by the modified Markov Chain Monte Carlo algorithm of Waldmann et al. (2013). This version has been chosen because of improved convergence;

- VA is a computational simplification of the Bayesian formulation with more restrictive Gaussian priors on the random effects and estimated using the variational approximation method of Waldmann and Kneib (2014). This provides a more restrictive model, but considerably reduces the computational costs.

The FE and CRE results are obtained by jointly estimating all the considered quantiles, while the Bayesian formulations are estimated on a quantile by quantile basis.

Overall, these different estimation methods produce similar results. The main difference resides in the confidence intervals, which are wider for the more general specifications and notably narrower for the more restrictive VA model. Interestingly, the MCMC model results agree with the VA results in the lower part of the conditional distribution, but converge to the FE and CRE results in the upper part. Bearing in mind that the Bayesian formulations impose independent random effects, this suggests that this assumption is more likely to be violated in the lower part of the distribution since it affects the results to a greater extent there.

The convergence effects (i.e. coefficient of lagged income) are shown on Figure 2a. In general, we only find conditional convergence (i.e. a negative coefficient) in the upper part of the distribution. This finding is consistent with Cunningham (2003), Barreto and 
This is a post-print of Kostov, P. and J. Le Gallo (2015) Convergence: a story of quantiles and spillovers, Kyklos, 68(4), 552-576. The definitive version is available at http://doi.org/10.1111/kykl.12093

Hughes (2004) and Canarella and Pollard (2004). In the lower part of the distribution the lagged income coefficient is not statistically significant, which indicates nonconvergence, but importantly does not exhibit divergence. Since the lagged income coefficient is in general decreasing (i.e. increasing in magnitude) with the quantile, when countries are converging the catching up countries are converging faster. However, the presence of non-converging countries (at the lower quantiles) is consistent with the phenomenon of convergence clubs.

[Figure 2 around here]

With respect to the control variables, first note that the effect of average savings (Figure $2 \mathrm{~b}$ ) is positive, as expected. This effect does not appear to be varying with quantiles with the possible exception of the lower tail where it appears to be larger. Intuitively, this makes sense because it means that larger investment in physical capital share leads to higher growth. Note that Barreto and Hughes (2004) find that the importance of investment share increases with quantiles and interpret this as a failure for underperformers to convert relative investment into economic growth. It is also at odds with the findings of Canarella and Pollard (2004) who only find significant coefficients for lower and higher quantiles. We do not confirm these results when using panel quantile techniques rather than cross-sectional ones.

The effect of (working) population growth (Figure 2c) is positive, but decreasing with quantile and becoming statistically insignificant in the upper part of the distribution. Hence, increasing workforce contributes to economic growth but up to a certain point. For conditionally slower growing economies this effect is larger and it reduces and totally disappears for faster growing ones. Labour intensive growth is therefore more beneficial to conditionally slower growing economies. For faster growth it is the quality (see next result) rather than the quantity of the workforce that accelerates growth.

Finally, a somewhat unexpected result is that the effect of the human capital on growth (Figure 2d) is insignificant except in the extreme upper tail of the conditional distribution where it is positive (as it is to be expected). This means that only the fastest growing (conditionally) economies are indeed able to translate investment in human capital in higher economic growth. Moreover, in the upper tail, the effect is increasing 
This is a post-print of Kostov, P. and J. Le Gallo (2015) Convergence: a story of quantiles and spillovers, Kyklos, 68(4), 552-576. The definitive version is available at http://doi.org/10.1111/kykl.12093

with quantile, so that the conditionally fastest growing countries are able to exploit human capital more effectively to further economic convergence. Again, this result does not follow that of Barreto and Hughes (2004) who found that the importance of secondary school attainment reaches a peak between the $30^{\text {th }}$ percentile and the median and then drops for higher percentiles. It is however closer to Canarella and Pollard (2004) who found that the estimates for human capital increase with quantiles and are not significant for lower quantiles.

\subsection{Spatial panel quantile models}

When comparing spatial models (or spatial and nonspatial ones), one uses the partial derivatives (see LeSage and Fischer, 2008). More specifically, since the partial derivatives vary with each observation, the average total impacts are useful in comparing such models. In linear spatial quantile models, the relationship assumes a linear functional form and hence the average total impacts can be computed in the same way as for the linear mean models (Kostov, 2013). Hereafter we will refer to these comparable effects (i.e. the average total quantile effects from the spatial models, as well as the coefficients from the nonspatial ones) simply as 'effects'.

Figure 3 shows a comparison between the effects from a non-spatial (FE) and the average total quantile impacts from spatial exogenous spatial weighting matrix estimators. The choice of estimators from each class is based on popularity (for the nonspatial) and realisticness (for the spatial one). The exogenous (case (iii) in section 3.2) and endogenous spatial weighting matrices model specifications were discussed above. The main purpose of Figure 3 is to provide an overall comparative perspective on the way results change with specification. It appears that using different versions of spatial and non-spatial panel quantile regression estimators does not change the qualitative conclusions drawn from such a comparison. The main conclusion is that the exogenous spatial specification results are broadly speaking compatible with the non-spatial model results. In general terms, these two sets of estimators produce comparable results and lead to similar conclusion. The main qualitative difference concerns the effect of human capital. While the non-spatial estimation only discovers positive effect of human capital in the extreme right (upper) tail of the conditional growth distribution, the spatial estimation locates such positive effects in larger part of the upper tail (approximately 
This is a post-print of Kostov, P. and J. Le Gallo (2015) Convergence: a story of quantiles and spillovers, Kyklos, 68(4), 552-576. The definitive version is available at http://doi.org/10.1111/kykl.12093

after the $0.85^{\text {th }}$ quantile). Therefore accounting for potential (exogenous) growth spillovers leads to a more widespread effect of human capital.

[Figure 3 around here]

The endogenous spatial model formulations however produce drastically different results. Figure 4 shows the estimated average total impacts form a range of spatial panel quantile models. We present results for one endogenous and the three exogenous spatial weighting matrix specifications, as discussed in section 3.2. Further results (on additional specifications) are available upon request.

It is important to note that the quantile impacts for spatial quantile autoregressions can only be compared qualitatively, rather than quantitatively. To understand this, consider equation (2). The conditional quantiles (3) are specified with regard to all covariates, including the spatial lag, i.e. they are also conditional on the assumed spatial spillover process. In other words faster growing economies in this case are the ones that grow faster given not only their endowments, but also the nature of the assumed spillover process.

In general terms, the total impacts from the presented (and omitted) exogenous specifications are similar and lead to the same conclusions. The other general difference is that as it is to be expected the confidence intervals for the endogenous spatial weighting matrix specification are considerably wider, accounting for the additional uncertainty embodied in the model. We now consider the differences between the endogenous and the exogenous cases on a variable-by-variable basis.

First, with respect to convergence, although the convergence effect in the endogenous specification is stronger (i.e. larger in magnitude) than in the exogenous specifications and its confidence intervals are much wider (Figure 4a), the qualitative conclusions are similar. Both types of specification show insignificant impact in the lower part of the growth distribution and significant negative impact in the upper part of the distribution. This implies only a partial conditional convergence (for the faster growing economies, but not for all). Further differences are worth noting. Indeed, in spite of the wider confidence intervals, the endogenous specification uncovers convergence effects in larger part of the distribution (these appear at around the $0.4^{\text {th }}$ quantile as opposed to 
This is a post-print of Kostov, P. and J. Le Gallo (2015) Convergence: a story of quantiles and spillovers, Kyklos, 68(4), 552-576. The definitive version is available at http://doi.org/10.1111/kykl.12093

the $0.5^{\text {th }}$ for the exogenous specification). Coupled with the larger magnitude of these one may say that endogenous spillovers imply 'more' convergence. Also, generally speaking in both specifications, convergence effects increase with quantile (which is to be expected). In terms of magnitude the endogenously derived convergence impacts are larger implying higher rates of convergence that those obtained from exogenous specifications.

[Figure 4 around here]

Second, with regard to savings (Figure $4 \mathrm{~b}$ ) both specifications show positive impacts, as expected. There seems to be difference in the size of the impacts in that the endogenously defined impact of investment shares are larger, but for the lower part of the distribution up to the 0.2th quantile where they are smaller. Hence endogenous spillovers lead to larger impact of investment by (endogenously) amplifying their impact relative to the lack of such endogenous mechanism. However this amplification (multiplier effect) only happens after a relative threshold in the conditional growth rate is reached (there is a jump in the impact at around the $0.2^{\text {th }}$ quantile). Therefore, we are able to recover evidence for potential investment 'traps'.

Third, the workforce impacts (Figure 4c) are similar for both types of specification. Owing to the wider confidence intervals in the endogenous case, these impacts are only significant between roughly the $0.25^{\text {th }}$ and the $0.4^{\text {th }}$ quantile (as opposed to most of the lower part of the growth distributions in the exogenous case).

Finally, it is with regard to the total impact of human capital (Figure 4d) where the difference between the endogenous and exogenous specification is striking. Note that the issue of measures of human capital and their potential effect is a subject to some controversy in the cross-country growth literature. The nature of the adopted proxies has been criticised (see e.g. Gemmell, 1996). The significance of this measure has also been shown to depend on sample and functional form choices. Previous studies have found either insignificant effects of human capital proxies (e.g. Benhabib and Spiegel, 1994) or negative effects (e.g. Islam, 1995; Caselli et al. 1996). The inconsistency in the previous results for human capital effect have been explained by the deployment of inappropriate assumptions about constant coefficient and linearity (Krueger and 
This is a post-print of Kostov, P. and J. Le Gallo (2015) Convergence: a story of quantiles and spillovers, Kyklos, 68(4), 552-576. The definitive version is available at http://doi.org/10.1111/kykl.12093

Lindahl, 2001) or measurement and functional form issues (Delgado et al.,2014). While for the exogenous specification the impact of human capital is only significantly positive in the upper tail (beyond the $0.85^{\text {th }}$ quantile), the impacts from the endogenous specification are positive across the whole distribution and considerably larger than those in the exogenous case. There appears to be an increase in the impacts in the upper tail implying that faster growing economies manage to better utilise their human capital. Recently Delgado et al. (2014) using non-parametric tests failed to discover significant effect of different human capital measure (years of schooling) but find strong evidence is support of human capital quality effects. One has to be careful in drawing parallels since their approach is univariate and focused on mean effects but our results appear to confirm such a conjecture. In particular the results from the non-spatial and the exogenous spatial weighting matrix model confirm the insignificance of the human capital measure for most of the conditional distribution, but the upward trend in the upper tail does suggest role for the quality of human capital. Its significance alongside the whole conditional distribution in the endogenous spillovers model on the other hand strongly supports the quality explanation. Since our endogenous spillovers specification is defined by wages (as factor income determining the market potential and ultimately the distance metric) if we assume that returns to labour are related to its quality, then our spillover specification implicitly includes the quality of human capital and hence one could expect it to be significant. The inability of the existing human capital measure to capture its quality, which is theoretically the driving force of the growth process, is a recurrent issue in the growth literature (see e.g Pritchett, 2001). Quality is hence a possible (and credible) explanation for these differences. Indeed, since the endogenous spatial weighting matrices are based on wage differences, they implicitly allow for interdependence between growth outcomes based on differences in labour returns, which is an implicit measure of labour quality.

\section{Conclusion}

This paper applies a spatial panel quantile regression models to the issue of conditional $\beta$-convergence. While previous analyses have taken into consideration spatial spillovers or have looked into the conditional growth distribution using quantile regression 
This is a post-print of Kostov, P. and J. Le Gallo (2015) Convergence: a story of quantiles and spillovers, Kyklos, 68(4), 552-576. The definitive version is available at http://doi.org/10.1111/kykl.12093

methods on cross-sectional data, we are the first to combine together both spatial spillovers and panel quantile analysis. This combination allows for deeper insights into the cross-country convergence process.

Our analysis shows that the nature and strength of the effects do not depend on this whether one assumes or not the presence of spillover effects, but on the nature of these spillovers. Assuming endogenous spillovers dramatically affects the estimates of the convergence process. Furthermore, the effect of human capital differs considerably between endogenous and exogenous spillover specifications. Our results suggest that the effect of human capital probably depends on its quality and the nature of the economy. We find evidence of conditional convergence amongst approximately half of the conditional growth distribution, while the rest do not demonstrate convergence. Interestingly we find no evidence for growth divergence.

Our specification does not include time dynamics. For this reason we cannot deduce whether they do not converge because they have already reached the steady state, or simply they are moving to a different steady state (club convergence). However the lack of non-convergence (positive lagged income effect) is quite important. It implies that even if there is club convergence, the different steady states are not entirely independent, but related since countries converging to a different steady state do not move away from the main one. 
This is a post-print of Kostov, P. and J. Le Gallo (2015) Convergence: a story of quantiles and spillovers, Kyklos, 68(4), 552-576. The definitive version is available at http://doi.org/10.1111/kykl.12093

\section{References}

Abrevaya J., Dahl C.M. (2008) The effects of birth inputs on birthweight: evidence from quantile estimation on panel data, Journal of Business and Economic Statistics, 26, 379-397.

Abreu M., de Groot H.L.F., Florax R.J.G.M. (2005) Space and growth: a survey of empirical evidence and methods, Région et Développement, $\mathrm{n}^{\circ} 21-2005,13-44$.

Bache S., Dahl C.M., Kristensen J.T. (2013) Headlights on tobacco road to low birthweight outcomes, Empirical Economics 44(3), 1593-1633.

Barreto R.A., Hughes A.W. (2004) Under performers and over achievers: a quantile regression analysis of growth, The Economic Record, 80(248), 17-35.

Barro R.J. (1991) Economic growth in a cross section of countries, The Quarterly Journal of Economics, 106(2), 407-443.

Barro R.J., Lee J.-W. (2010) A new data set of educational attainment in the world, 19502010, NBER Working Paper Nº 15902.

Benhabib, J. and M. M Spiegel (1994) The role of human capital in economic development evidence from aggregate cross-country data, Journal of Monetary Economics, 34 (2), 143-173.

Canarella G., Pollard S. (2004) Parameter heterogeneity in the neoclassical growth model: a quantile regression approach, Journal of Economic Development, 29(1), 1-31.

Canay I.A. (2011), A simple approach to quantile regression for panel data, Econometrics Journal, 14, 368-386.

Caselli, F., G. Esquivel and F. Lefort, (1996). Reopening the Convergence Debate: A New Look at Cross-Country Growth Empirics, Journal of Economic Growth, 1(3), 363-89.

Chamberlain G. (1982) Multivariate regression models for panel data, Journal of Econometrics, 18, 5-46.

Chen Y.J., Deng W.S, Yang T.C., Mathews S.A. (2012) Geographically weighted quantile regression (GWQR): An application to US mortality data, Geographical Analysis, 44(2), 134-150. 
This is a post-print of Kostov, P. and J. Le Gallo (2015) Convergence: a story of quantiles and spillovers, Kyklos, 68(4), 552-576. The definitive version is available at http://doi.org/10.1111/kykl.12093

Chernozhukov V., Hansen C. (2005) An IV model of quantile treatment effects. Econometrica, 73, 245-261.

Chernozhukov V., Hansen C. (2006) Instrumental quantile regression inference for structural and treatment effects models, Journal of Econometrics, 132, 491-525.

Chernozhukov V., Fernandez-Val I., Hahn J., Newey W. (2009) Identification and estimation of marginal effects in nonlinear panel models, CeMMAP working papers CWP05/09, Centre for Microdata Methods and Practice, Institute for Fiscal Studies.

Cunningham B.M. (2003) The distributional heterogeneity of growth effects: some evidence, The Manchester School, 71, 417-447.

Delgado, M. S., Henderson D. J., Parmeter, C. F. (2014) Does education matter for economic growth? Oxford Bulletin of Economics and Statistics, 76(3), 334-359.

Dufrenot G., Mignon V., Tsangarides C. (2010) The trade-growth nexus in the developing countries: a quantile regression approach, Review of World Economics, 146, 731-761.

Desdoigts A. (1999) Patterns of economic development and the formation of clubs, Journal of Economic Growth, 4, 305-330.

Durlauf S.N. (2000) Econometric analysis and the study of growth: a skeptical perspective, in Blackhouse R., Salanti A. (Eds.), Macroeconomics and the Real World, Oxford, Oxford University Press.

Durlauf S.N., Johnson P.A. (1995) Multiple regimes and cross-country growth behaviour, Journal of Applied Econometrics, 10, 365-384.

Ertur C., Le Gallo J. (2009) Regional growth and convergence: heterogeneous reaction versus interaction in spatial econometric approaches, in: Capello R., Nijkamp P. (Eds.), Regional Dynamics and Growth, Edward Elgar.

Foster N. (2008) The impact of trade liberalisation on economic growth: evidence from a quantile regression analysis, Kyklos, 61(4), 543-567.

Gemmell, N. (1996) Evaluating the impacts of human capital stocks and accumulation on economic growth: some new evidence, Oxford Bulletin of Economics and Statistics, 58(1), 9-28.

Hallin M., Lu Z., Yu K. (2009) Local linear spatial quantile regression, Bernoulli, 15(3), 659-686.

Harding M., Lamarche C. (2009) A quantile regression approach for estimating panel data models using instrumental variables, Economics Letters, 104(3), 133-135. 
This is a post-print of Kostov, P. and J. Le Gallo (2015) Convergence: a story of quantiles and spillovers, Kyklos, 68(4), 552-576. The definitive version is available at http://doi.org/10.1111/kykl.12093

Head K., Mayer T. (2004) Market Potential and the location of Japanese investment in the European Union, The Review of Economics and Statistics, 86(4), 959-972.

Heston A., Summers R., Aten B. (2012) Penn World Table Version 7.1, Center for International Comparisons of Production, Income and Prices at the University of Pennsylvania.

Islam N. (1995) Growth empirics: A panel data approach, The Quarterly Journal of Economics, 110(4), 1127-1170.

Kelejian H.H., Piras G. (2014) Estimation of spatial models with endogenous weighting matrices and an application to a demand model for cigarettes, Regional Science and Urban Economics, 46, 140-149.

Kelejian H.H., Prucha I.R. (2010) Specification and estimation of spatial autoregressive models with autoregressive and heteroskedastic disturbances, Journal of Econometrics, 157, 53-67.

Kim T.H., Muller C. (2004) Two-stage quantile regression when the first stage is based on quantile regression, The Econometric Journal, 7, 218-231.

Koenker, R. (2004) Quantile regression for longitudinal data, Journal of Multivariate Analysis, 91, 74-89.

Kostov P. (2009) A spatial quantile regression hedonic model of agricultural land prices, Spatial Economic Analysis, 4(1), 53-72.

Kostov P. (2013) Empirical likelihood estimation of the spatial quantile regression, Journal of Geographical Systems, 15(1), 51-69.

Kostov P., Davidova S. (2013) A quantile regression analysis of the effect of farmers' attitudes and perceptions on market participation, Journal of Agricultural Economics, 64(1), 112-132

Kozumi H., Kobayashi G. (2009) Gibbs sampling methods for Bayesian quantile regression, Technical report, Kobe University.

Krueger A. B., and M. Lindahl (2001). Education for Growth: Why and for Whom?, Journal of Economic Literature, 39(4), 1101-1136.

Lamarche C. (2010) Robust penalized quantile regression estimation for panel data, Journal of Econometrics, 157(2), 396-408.

Lee S. (2007) Endogeneity in quantile regression models: A control function approach, Journal of Econometrics, 141(2), 1131-1158. 
This is a post-print of Kostov, P. and J. Le Gallo (2015) Convergence: a story of quantiles and spillovers, Kyklos, 68(4), 552-576. The definitive version is available at http://doi.org/10.1111/kykl.12093

Levine R., Renelt D. (1992) A sensitivity analysis of cross-country growth regressions, American Economic Review, 82(4), 942-963.

LeSage J. P., Fischer M.M. (2008) Spatial growth regressions: model specification, estimation and interpretation, Spatial Economic Analysis, 3(3), 275-304.

Liao W.-C., Wang X. (2012) Hedonic house prices and spatial quantile regression, Journal of Housing Economics, 21(1), 16-28.

Liu S., Hite D. (2013) Measuring the effect of green space on property value: An application of the hedonic spatial quantile regression, Southern Agricultural Economics Association, 2013 Annual Meeting, February 2-5, 2013, Orlando, Florida.

Lum K., Gelfand A.E. (2012) Spatial quantile multiple regression using the asymmetric Laplace process, Bayesian Analysis, 7(2), 235-258.

Mankiw N.G., Romer D., Weil D.N. (1992) A contribution to the empirics of economic growth, Quarterly Journal of Economics, 107, 407-437.

Mayer T. (2009) Market potential and development, Working paper 2009 - 24, CEPII.

Pritchett L. (2001) Where Has All the Education Gone? World Bank Economic Review 15 (3), 367-391.

Ram R. (2008) Parametric variability in cross-country growth regressions: an application of quantile-regression methodology, Economics Letters, 99, 387-389.

Redding, S., Venables A. (2004) Economic geography and international inequality, Journal of International Economics, 62(1), 53-82.

Reich B.J., Fuentes M., Dunson D.B. (2011) Bayesian spatial quantile regression, Journal of the American Statistical Association, 106, 6-20.

Reed C., Yu K. (2009) A partially collapsed Gibbs sampler for Bayesian quantile regression. Technical report. Department of Mathematical Sciences, Brunel University.

Rey S.J., Le Gallo J. (2009) Spatial analysis of economic convergence, in: Mills T.C., Patterson K. (Eds.), The Palgrave Handbook of Econometrics, volume II : Applied Econometrics, Palgrave MacMillan.

Rosen A. (2009) Set identification via quantile restrictions in short panels CeMMAP working papers CWP26/09, Centre for Microdata Methods and Practice, Institute for Fiscal Studies. 
This is a post-print of Kostov, P. and J. Le Gallo (2015) Convergence: a story of quantiles and spillovers, Kyklos, 68(4), 552-576. The definitive version is available at http://doi.org/10.1111/kykl.12093

Su L., Yang Z. (2011) Instrumental variable quantile estimation of spatial autoregressive models, Working paper, School of Economics, Singapore Management University, http://www.mysmu.edu/faculty/ljsu/Publications/ivqr_sar20110505.pdf

Temple J. (1998) Robustness tests of the augmented Solow model, Journal of Applied Econometrics, 13, 361-375.

Waldmann E., Kneib T. (2014) Variational approximations in geoadditive latent gaussian regression: mean and quantile regression. Statistics and Computing, Doi: 10.1007/s11222-014-9480-2

Waldmann E., Kneib T., Yue Y., Lang S., Flexeder C. (2013) Bayesian semiparametric additive quantile regression, Statistical Modelling, 13, 223-252.

Yu K., Moyeed R.A. (2001). Bayesian quantile regression, Statistics and Probability Letters, 54, 437-447.

Yuan Y., Yin G. (2010) Bayesian quantile regression for longitudinal studies with nonignorable missing data. Biometrics, 66, 105-114.

Yue Y., Rue H. (2011) Bayesian inference for additive mixed quantile regression models. Computational Statistics and Data Analysis, 55, 84-96.

Zietz J., Zietz E.N., Sirmans G.S. (2008) Determinant of housing prices: A quantile regression approach, Journal of Real Estate Finance and Economics, 37, 317-333. 
This is a post-print of Kostov, P. and J. Le Gallo (2015) Convergence: a story of quantiles and spillovers, Kyklos, 68(4), 552-576. The definitive version is available at http://doi.org/10.1111/kykl.12093

\section{Figures}

Figure 1. Comparison of the main estimator with conventional estimators
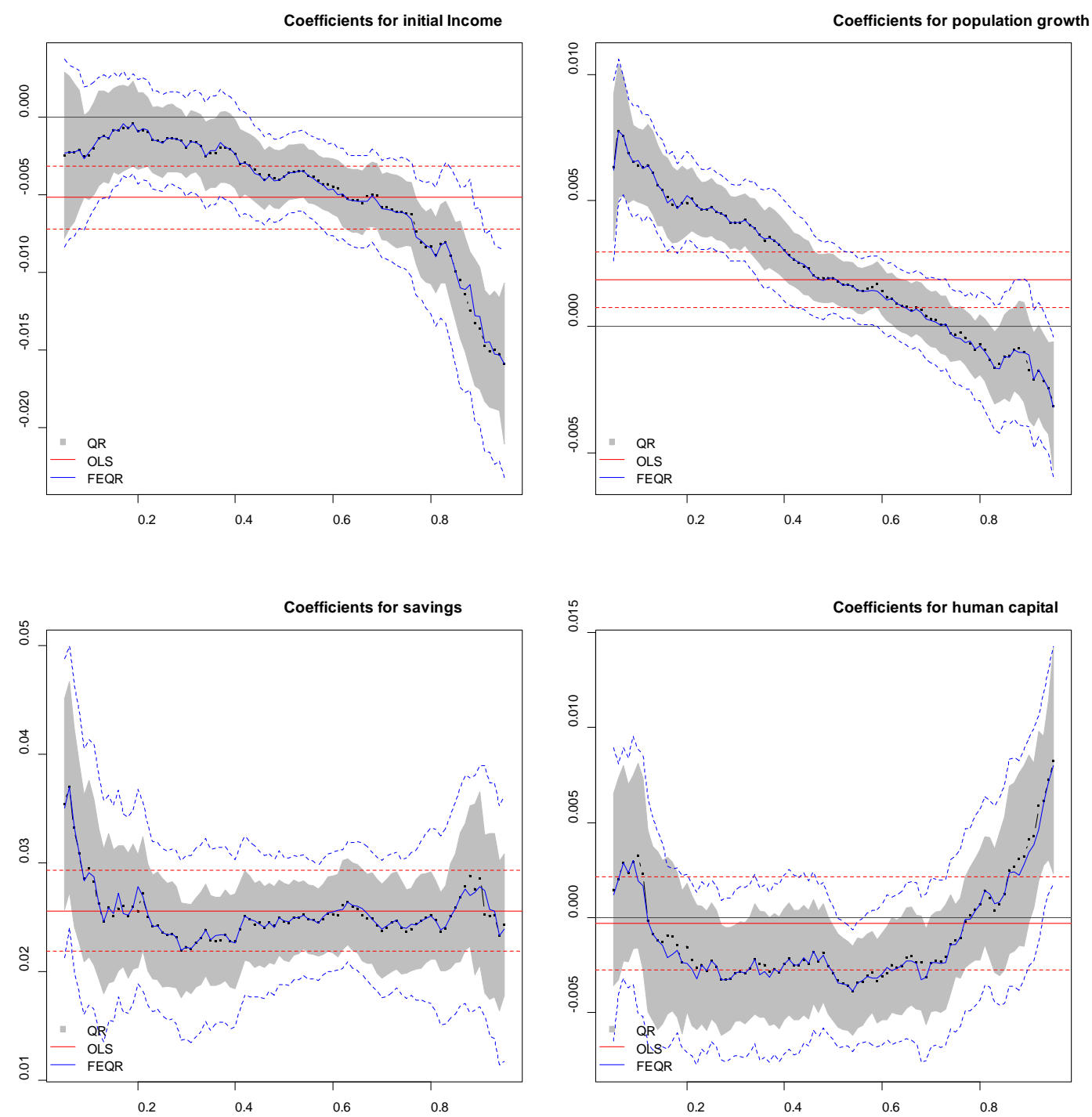

Notes:

QR - quantile regression

OLS - linear model

FEQR - fixed effects quantile regression

Dotted lines (and shaded area for the QR estimator) show the corresponding confidence intervals 
This is a post-print of Kostov, P. and J. Le Gallo (2015) Convergence: a story of quantiles and spillovers, Kyklos, 68(4), 552-576. The definitive version is available at http://doi.org/10.1111/kykl.12093

Figure 2 Results from non-spatial panel quantile models
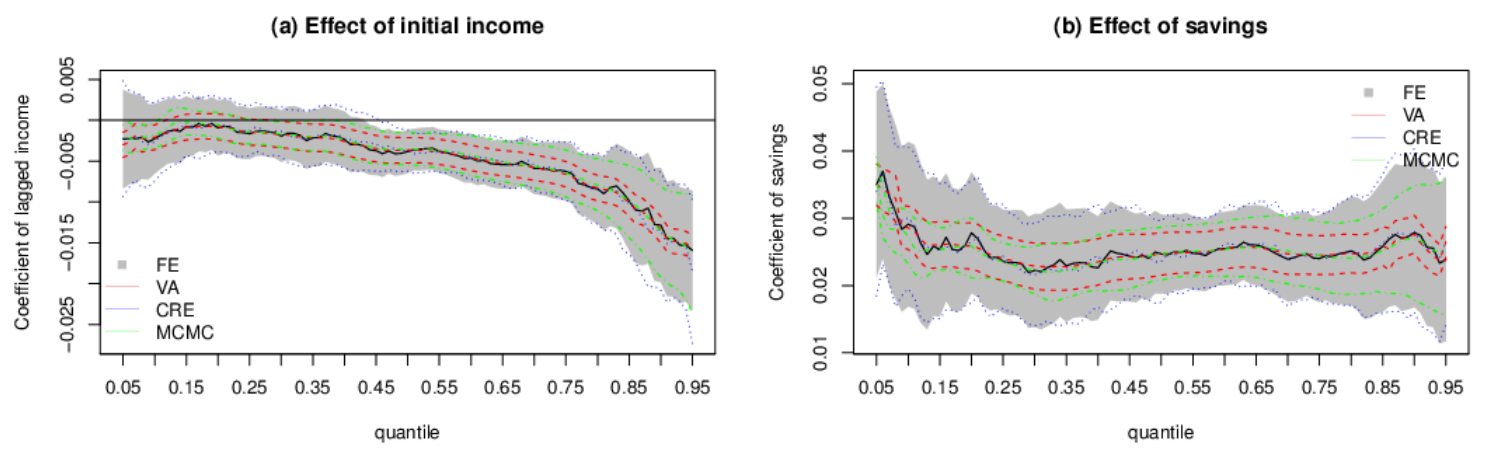

(c) Effect of population growth

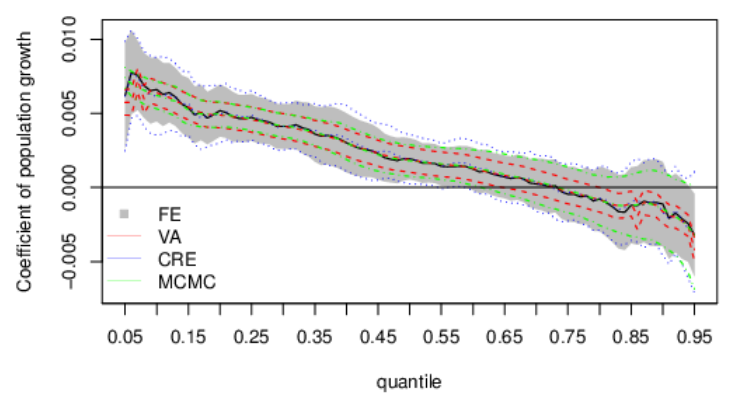

(d) Effect of human capital

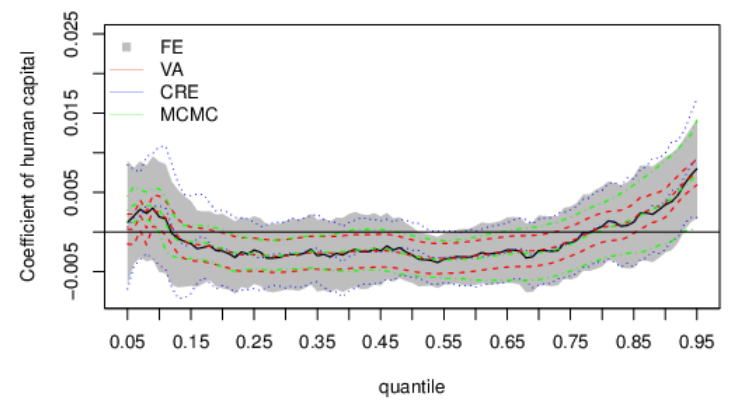

Notes:

FE - fixed effects quantile regression

VA - random effects quantile regression estimated via variational approximation CRE - correlated random effects

MCMC - random effects quantile regression estimated via Markov Chain Monte Carlo

Dotted lines (and shaded area for the FE estimator) show the corresponding confidence intervals 
This is a post-print of Kostov, P. and J. Le Gallo (2015) Convergence: a story of quantiles and spillovers, Kyklos, 68(4), 552-576. The definitive version is available at http://doi.org/10.1111/kykl.12093

Figure 3. Comparison of spatial and non-spatial panel quantile models
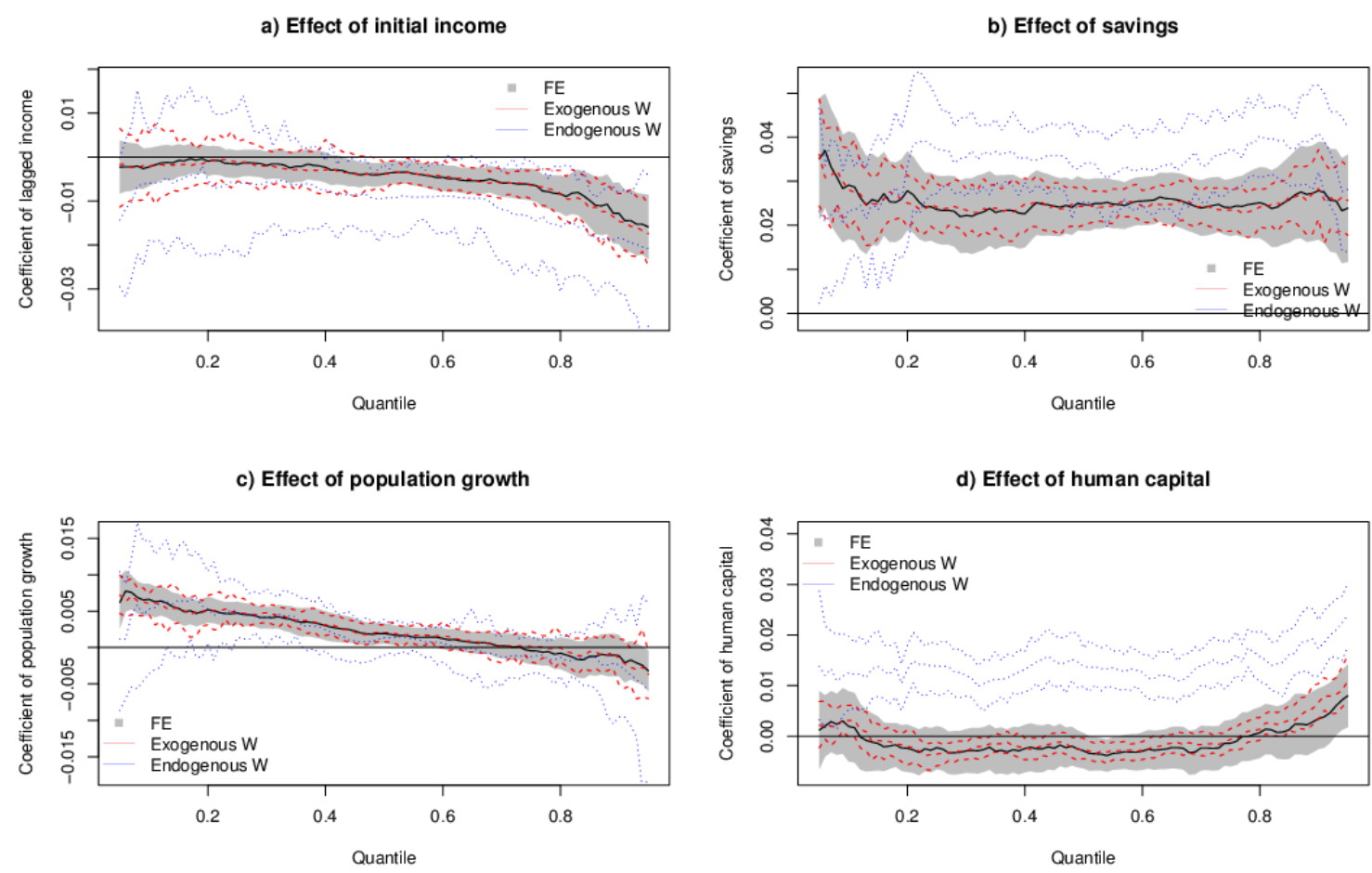

Notes:

FE - fixed effects quantile regression (non-spatial model)

Exogenous W- Spatial model with exogenous spatial weighting matrix

Endogenous W - Spatial model with endogenous spatial weighting matrix.

The spatial models results present the total average quantile effects.

Dotted lines (and shaded area for the FE estimator) show the corresponding confidence intervals 
This is a post-print of Kostov, P. and J. Le Gallo (2015) Convergence: a story of quantiles and spillovers, Kyklos, 68(4), 552-576. The definitive version is available at http://doi.org/10.1111/kykl.12093

Figure 4. Spatial panel quantile model results

a) Total impact of initial income

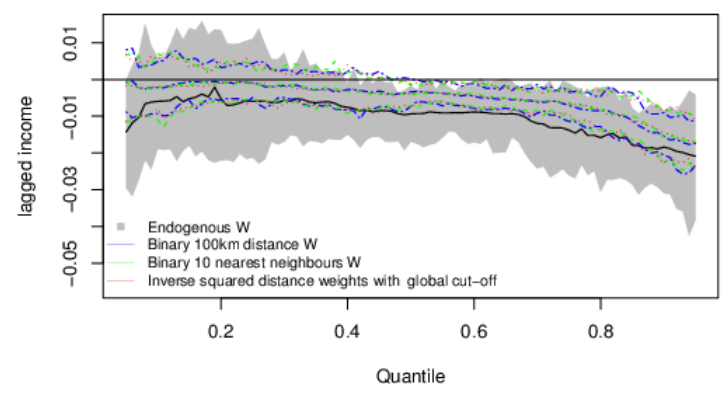

c) Total impact of population growth

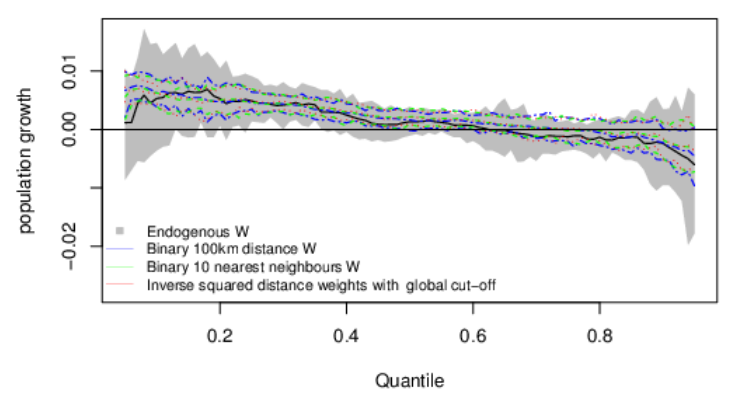

b) Total impact of savings

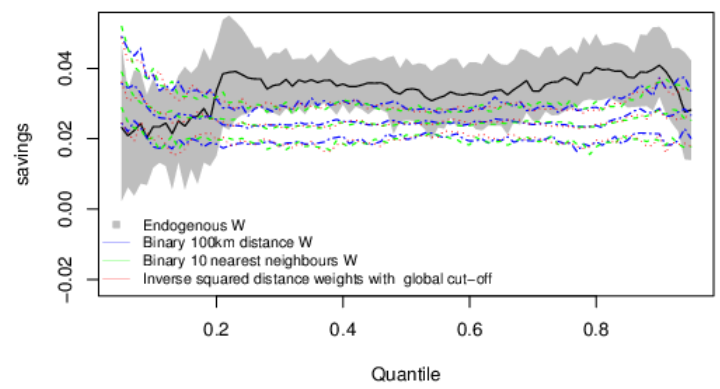

d) Total impact of human capital

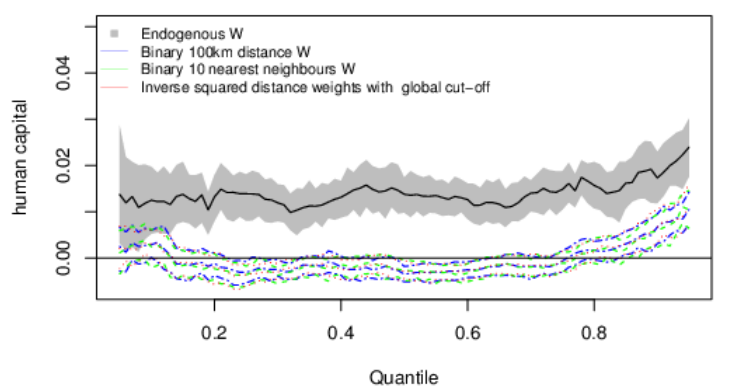

Notes:

Endogenous $\mathrm{W}$ - Spatial model with endogenous spatial weighting matrix.

Binary $100 \mathrm{~km}$ distance $\mathrm{W}-$ Spatial model with a binary spatial weighting matrix based on $100 \mathrm{~km}$ definition of neighbourhood.

Binary 10 nearest neighbours $\mathrm{W}$ - Spatial model with a binary spatial weighting matrix based on the 10 nearest neighbours.

Inverse squared distance weights with global cut-off - Spatial model with spatial weighting matrix constructed from inverse squared distance weights by applying a global cut-off.

The estimates refer to the total average quantile effects.

Dotted lines (and shaded area for the endogenous specification) show the corresponding confidence intervals 
This is a post-print of Kostov, P. and J. Le Gallo (2015) Convergence: a story of quantiles and spillovers, Kyklos, 68(4), 552-576. The definitive version is available at http://doi.org/10.1111/kykl.12093

Appendix 1

Table S.1. Countries in the dataset and years of availability

\begin{tabular}{|c|c|c|}
\hline \multirow[t]{2}{*}{ Country } & \multicolumn{2}{|c|}{ Years of availability } \\
\hline & $\begin{array}{c}\text { Non-spatial models and } \\
\text { Spatial models } \\
\text { with exogenous } W\end{array}$ & $\begin{array}{c}\text { Spatial models } \\
\text { with endogenous } W\end{array}$ \\
\hline Afghanistan & $1975-2010$ & $1980-1985$ \\
\hline Albania & $1975-2010$ & 1990-2005 \\
\hline Algeria & $1965-2010$ & 1980-1995 \\
\hline Argentina & $1955-2010$ & $1985-2000$ \\
\hline Armenia & $2000-2010$ & - \\
\hline Australia & $1955-2010$ & $1980-2000$ \\
\hline Austria & $1955-2010$ & $1980-2005$ \\
\hline Bahrain & $1975-2010$ & - \\
\hline Bangladesh & $1965-2010$ & 1980-1995 \\
\hline Barbados & $1965-2010$ & 1980-1995 \\
\hline Belgium & $1955-2010$ & - \\
\hline Belize & $1975-2010$ & - \\
\hline Benin & $1965-2010$ & $1980-1980$ \\
\hline Bolivia & $1955-2010$ & $1980-2000$ \\
\hline Botswana & $1965-2010$ & - \\
\hline Brazil & $1955-2010$ & $1990-2005$ \\
\hline Bulgaria & $1975-2010$ & $1980-2005$ \\
\hline Burundi & $1965-2010$ & $1980-1990$ \\
\hline Cambodia & $1975-2010$ & $1995-2000$ \\
\hline Cameroon & $1965-2010$ & $1980-2000$ \\
\hline Canada & $1955-2010$ & $1980-2000$ \\
\hline $\begin{array}{c}\text { Central African } \\
\text { Republic }\end{array}$ & $1965-2010$ & - \\
\hline Chile & $1960-2010$ & $1980-2000$ \\
\hline Colombia & $1955-2010$ & $1980-2000$ \\
\hline Costa Rica & $1955-2010$ & $1985-2000$ \\
\hline Croatia & $2000-2010$ & 1995-2005 \\
\hline Cuba & $1975-2010$ & $1980-1985$ \\
\hline Cyprus & $1955-2010$ & 1980-2005 \\
\hline Czech Republic & $1995-2010$ & $1995-2005$ \\
\hline Denmark & $1955-2010$ & $1980-2005$ \\
\hline Ecuador & $1960-2010$ & $1980-2005$ \\
\hline Egypt & $1955-2010$ & 1980-1995 \\
\hline El Salvador & $1955-2010$ & 1980-1995 \\
\hline Estonia & $1995-2010$ & $2000-2005$ \\
\hline
\end{tabular}


This is a post-print of Kostov, P. and J. Le Gallo (2015) Convergence: a story of quantiles and spillovers, Kyklos, 68(4), 552-576. The definitive version is available at http://doi.org/10.1111/kykl.12093

\begin{tabular}{|c|c|c|}
\hline Fiji & $1965-2010$ & $1980-1990$ \\
\hline Finland & $1955-2010$ & $1980-2000$ \\
\hline France & $1955-2010$ & $1980-2005$ \\
\hline Gabon & $1965-2010$ & $1980-1995$ \\
\hline Ghana & $1960-2010$ & $1980-2005$ \\
\hline Greece & $1960-2010$ & 1980-1995 \\
\hline Guatemala & $1955-2010$ & $1980-1995$ \\
\hline Guyana & $1980-2010$ & - \\
\hline Haiti & $1965-2010$ & $1980-1995$ \\
\hline Honduras & $1955-2010$ & $1985-1995$ \\
\hline Hungary & $1975-2010$ & $1980-2000$ \\
\hline Iceland & $1955-2010$ & $1980-1995$ \\
\hline India & $1955-2010$ & $1980-2005$ \\
\hline Indonesia & $1965-2010$ & $1980-2005$ \\
\hline Iraq & $1975-2010$ & $1980-1985$ \\
\hline Ireland & $1955-2010$ & $1980-2000$ \\
\hline Israel & $1955-2010$ & $1980-2005$ \\
\hline Italy & $1955-2010$ & $1980-2005$ \\
\hline Jamaica & $1960-2010$ & $1980-1990$ \\
\hline Japan & $1955-2010$ & $1980-2000$ \\
\hline Jordan & $1960-2010$ & $1980-2005$ \\
\hline Kazakhstan & $2000-2010$ & $2000-2005$ \\
\hline Kenya & $1955-2010$ & $1980-2005$ \\
\hline Kuwait & $2000-2010$ & $2000-2000$ \\
\hline Kyrgyzstan & $2000-2010$ & $2000-2005$ \\
\hline Latvia & $2000-2010$ & $2000-2005$ \\
\hline Lesotho & $1965-2010$ & - \\
\hline Liberia & $1975-2010$ & $1985-1985$ \\
\hline Lithuania & $2000-2010$ & $2000-2005$ \\
\hline Luxembourg & $1955-2010$ & - \\
\hline Malawi & $1960-2010$ & $1980-2000$ \\
\hline Malaysia & $1960-2010$ & $1980-2005$ \\
\hline Maldives & $1975-2010$ & - \\
\hline Mali & $1965-2010$ & - \\
\hline Malta & $1975-2010$ & $1980-2005$ \\
\hline Mauritania & $1965-2010$ & - \\
\hline Mauritius & $1955-2010$ & $1980-2000$ \\
\hline Mexico & $1955-2010$ & $1980-2000$ \\
\hline Mongolia & $1975-2010$ & $1990-2000$ \\
\hline Morocco & $1955-2919$ & $1980-2005$ \\
\hline Mozambique & $1965-2010$ & $1990-2000$ \\
\hline Namibia & $1965-2010$ & - \\
\hline Nepal & $1965-2010$ & $1990-1990$ \\
\hline Netherlands & $1955-2010$ & $1980-2005$ \\
\hline
\end{tabular}


This is a post-print of Kostov, P. and J. Le Gallo (2015) Convergence: a story of quantiles and spillovers, Kyklos, 68(4), 552-576. The definitive version is available at http://doi.org/10.1111/kykl.12093

\begin{tabular}{|c|c|c|}
\hline New Zealand & $1955-2010$ & $1980-1995$ \\
\hline Nicaragua & $1955-2010$ & $1980-1985$ \\
\hline Niger & $1965-2010$ & $2000-2005$ \\
\hline Norway & $1955-2010$ & $1980-2000$ \\
\hline Pakistan & $1955-2010$ & $1980-1990$ \\
\hline Panama & 1955-2010 & $1980-2000$ \\
\hline Papua New Guinea & $1965-2010$ & $1980-1985$ \\
\hline Paraguay & $1960-2010$ & - \\
\hline Peru & $1955-2010$ & $1985-1995$ \\
\hline Philippines & $1955-2010$ & $1980-2005$ \\
\hline Poland & $1975-2010$ & $1980-2000$ \\
\hline Portugal & $1955-2010$ & $1980-2005$ \\
\hline Qatar & $1995-2010$ & $2000-2005$ \\
\hline Rwanda & $1965-2010$ & $1985-1985$ \\
\hline Saudi Arabia & $1995-2010$ & - \\
\hline Senegal & $1965-2010$ & $1980-2000$ \\
\hline Sierra Leone & $1970-2010$ & - \\
\hline Singapore & $1965-2010$ & $1980-2005$ \\
\hline Slovenia & 1995-2010 & $1995-2000$ \\
\hline South Africa & $1955-2010$ & $1980-2005$ \\
\hline Spain & $1955-2010$ & $1980-2005$ \\
\hline Sri Lanka & $1955-2010$ & $1980-2000$ \\
\hline Sudan & $1975-2010$ & - \\
\hline Swaziland & $1975-2010$ & - \\
\hline Sweden & $1960-2010$ & $1980-2000$ \\
\hline Switzerland & $1955-2010$ & $2000-2000$ \\
\hline Taiwan & $1960-2010$ & $1980-1995$ \\
\hline Tajikistan & $2000-2010$ & - \\
\hline Thailand & $1955-2010$ & $1990-2000$ \\
\hline Togo & $1965-2010$ & $1980-1980$ \\
\hline Tonga & $1985-2010$ & $1985-2005$ \\
\hline Tunisia & $1970-2010$ & $1980-2005$ \\
\hline Turkey & $1955-2010$ & $1980-2000$ \\
\hline Uganda & $1955-2010$ & $1985-2000$ \\
\hline Ukraine & $1955-2010$ & $2000-2005$ \\
\hline United Arab Emirates & $1995-2010$ & - \\
\hline United Kingdom & $1955-2010$ & $1980-2005$ \\
\hline Uruguay & $1955-2010$ & $1980-2005$ \\
\hline Venezuela & $1955-2010$ & $1980-1995$ \\
\hline Yemen & $1995-2010$ & $2000-2005$ \\
\hline Zambia & $1960-2010$ & $1980-1990$ \\
\hline Zimbabwe & $1960-2010$ & 1980-1995 \\
\hline
\end{tabular}

